\section{THE DIRECT HEAT TREATMENT OF CEMENT MILL DUST TO INCREASE ITS WATER-SOLUBLE POTASH CONTENT}

By ALBERT R. MERz

Received November 9, 1917

When a potash-containing silicate mixed with lime is ignited at temperatures above $1000^{\circ}$, the lime displaces more or less potash which is volatilized. This fact suggests a possible procedure for the immediate commercial production of potash from potash silicates. - Since, however, commercial grades of any insoluble potash silicate in quantity contain comparatively small percentages of potash no process for recovering potash from such material can offer much promise of profitable application unless there is also produced some other product of value in addition to the potash. Fortunately, and by strange coincidence, the two manufacturing industries of this country which have the largest outputs are industries wherein raw materials which contain potash silicates are heated with limestone to temperatures so high that the potash is more or less displaced and volatilized. These two industries, viz., the blast-furnace and Portland cement industries, are already firmly established and for them the problem becomes merely one of the successful recovery of the volatilized potash as a by-product. It may be stated that the chief potential source of potash in this country is the raw material which is or may be used in these industries.

Some potash is contained in all cement materials. In a recent publication by this. Bureaut it was shown that in the raw mix as fed into the kiln the potash varies from 0.20 to 1.16 per cent in the various cement mills of the United States and Canada, and that the percentage of this potash driven from the kilns in the different plants varies from 24.5 to 95.9. From the results of the analysis of samples of raw mix and of cement from $\mathrm{IO}_{2}$ plants it has been calculated that the potash escaping from the kilns of these plants ranges from 0.35 to 5 .I 4 lbs. per barrel of cement produced with an average for the plants of. this country of $1.93 \mathrm{lbs}$. On the basis of an average production of $90,000,000 \mathrm{bbls}$, the total potash escaping from the cement plants of this country, as at present operated, amounts to about 87,000 tons annually. The profitable recovery of this potash is not dependent upon successful collection alone, but it must be obtained in a form so concentrated as to be merchantable and at a cost sufficiently low to permit of a profit under normal market conditions. Three factors determine such profitable recovery and must be considered in any attempt advantageously to obtain potash as a by-product in the cement industry: liberation of the potash, recombination and collection.

A full discussion of the various conditions which affect the liberation of potash from the raw mix in the kiln and of the methods which have been devised to increase the percentage of potash volatilized is to be found in the publication already mentioned. Similarly the methods of collection of the potash that escapes from the kilns have received ample treatment in this

1 W. H. Ross, A. R. Merz and C. R. Wagner, U. S. Department of Agriculture, Bull, 572 . bulletin. The work presented here deals with a method for making water-soluble the "recombined" potash of cement dust.

The recovery of the potash which escapes from the kilns of cement mills was first made by the Riverside Portland Cement Co., at Riverside, Cal., using the Cottrell process of electrical, precipitation. The cement dust recovered at this plant was found to contain upward of 90 per cent of its potash in the water-soluble form. A sample of precipitator dust secured from this mill was analyzed by the author and found to give a total potash content of ro.7 per cent, and a water-soluble potash content of 9.8 per cent. The water-soluble potash of this particular dust was 92 per cent of the total potash present in the dust. It was natural to expect that the dust which would be recovered by a similar method at other plants would have a watersoluble potash content approximating the same percentage of the total potash present. It was found, however, when the Cottrell process was installed at the mill of the Security Cement and Lime Company, at Hagerstown, Md., that the dust collected contained a considerable portion of its potash content in a form which was not readily soluble in water. A sample of dust obtained from this plant was found to contain II.4 per cent total potash, whereas the water-soluble potash content was but 6.8 per cent. Instead of the anticipated 90 per cent or over, this particular sample of dust contained but 60 per cent of its potash in water-soluble form. It has been found at another plant, the Alpha Portland Cement Company at Cementon, N. Y., where installation of the Cottrell process for the recovery of dust has been made, that the watersoluble potash in the dust recovered constitutes a considerably lower proportion of the total potash present than at the Security plant. A sample of the dust recovered at this mill was found by the author to contain 7.0 per cent total potash and only 2.9 per cent watersoluble potash This sample of dust, therefore, had but $4 \mathrm{I}$ per cent of its potash present in the watersoluble form.

The term "water-soluble potash" as used above refers to that potash which is obtained in solution by the procedure given in the "Methods of the Association of Official Agricultural Chemists," in accordance with which ro $\mathrm{g}$. of the sample are boiled with $300 \mathrm{cc}$. of water for $30 \mathrm{~min}$. and the volume subsequently brought to $500 \mathrm{cc}$. As it is customary in the fertilizer trade to make payment for none other than this potash it becomes a matter of vital importance to the cement manufacturer who recovers his dust for sale to the fertilizer trade on the basis of its water-soluble potash content to ascertain the cause of the failure to secure the maximum amount of his potash in this form, to devise methods, if possible, to obtain most of the potash in his dust directly as water-soluble potash, to adopt some procedure which will profitably increase the water-soluble potash of his dust as at present obtained or, finally, to endeavor to secure from the fertilizer trade credit for that available potash of his dust which is but slowly water-soluble and for which at present he receives no compensation. 
As stated in a previous publication, ${ }^{1}$ the potassium compounds occurring in cement dust may be divided into three groups: (I) those which are readily watersoluble; (2) those which are slowly soluble; and (3) those which are insoluble.

The insoluble potash represents the combinations occurring in the original silicates of the raw mix carried over mechanically in the dust before being subjected to a temperature sufficiently high to bring about decomposition. The form of combination which is slowly soluble in water has been attributed to the recombination of the volatilized potash with the finely divided incandescent particles of siliceous coal ash carried over in the dust ${ }^{2}$ and it is claimed ${ }^{3}$ to be proportional to the amount of coal ash present in the gases from the kiln. Where oil or gas is used for fuel this combination of the potash occurs in comparatively small a mount but, where coal is used for burning, the extent to which the potash occurs in this "recombined" form may be considerable. Of the three cement $p$ 'ants mentioned above, the Riverside Portland Cement Company uses oil for fuel while the Security Cement and Lime Company and the Alpha Portland Cement Company use coal in their operation. The insoluble potash is assumed to be that portion of the total potash which remains undissolved after the dust is boiled in a 5 per cent solution of hydrochloric acid. The difference between the total potash and the sum of the watersoluble and insoluble portions is taken as the slowly soluble or recombined potash. It has been shown by Nestell and Anderson ${ }^{4}$ that continued extraction of cement dust with boiling water for ro hrs. is sufficient to dissolve practically all this slowly soluble potash.

Various methods have been tried to prevent the recombination of potash and it is reported by J. J. Porter, ${ }^{4}$ of the Security Cement and Lime Company, that the use of salt has been found beneficial in this connection.

In a publication by W. H. Ross ${ }^{5}$ it was shown that when feldspar and lime are digested with water under a steam pressure of Io to 5 atmospheres about 90 per cent of the potash in the feldspar passes into solution. In cement dust as it escapes from the kilns, the slowly soluble and insoluble potash are already associated with a considerable percentage of free lime and consequently he concluded that the greater part of the constituents might be recovered in water-soluble form by digesting the dust with steam under pressure. Experimental work has shown this to be the case and the results obtained by this procedure will be published separately.

Since ignition of a potash-containing silicate in the presence of lime liberates potash and since the cement dust, as has already been stated, contains a considerable proportion of free lime, it occurred to the author that the recombined potash might be rendered watersoluble by simple ignition of the dust. A preliminary

${ }^{1}$ W. H. Ross and A. R. Merz, This JournAI, 9 (1917), 1035.

2 R. J. Nestell and E. Anderson, Ibid., 9 (1917), 646.

3 J. J. Porter, paper presented at the meeting of the Portland Cement Association, Chicago, September, 1917.

4 Loe. cit.

5 This Journal, 9 (1917), 467. experiment was carried out in which a sample of the above-mentioned treater dust from the Security Cement and Lime Company was ignited with an equal weight of calcium carbonate in a $\mathrm{J}$. Lawrence Smith crucible at about $1000^{\circ}$ for a period of 40 minutes. The watersoluble potash was found to have been increased by this treatment from 6.8 to 10.4 per cent on the basis of the original sample. In other words, the watersoluble potash had been increased from 60 per cent to 9 I per cent of the total potash content. The addition of calcium carbonate served, however, to considerably

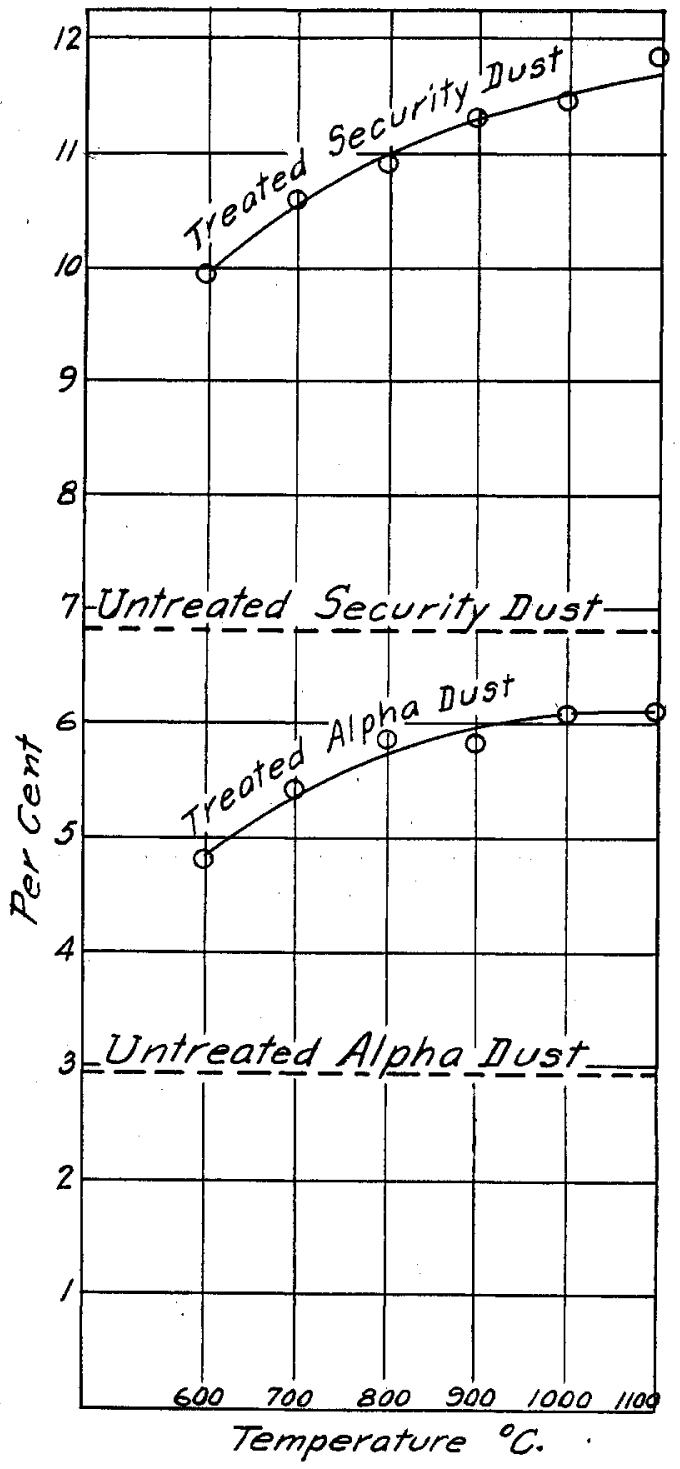

Fig. I-Percentages of Water-Sol,uble Potash in Untreated and TrEated Dusts

lower the percentage of water-soluble potash in the resultant product so that the latter contained 7.I per cent of water-soluble potash. It is possible that a procedure somewhat similar to this on a large scale should prove profitable to the cement manufacturer who at present receives nothing for his recombined potash, for although he has not appreciably increased the percentage of water-soluble potash in the material he sells, he has increased the quantity of his product over 40 per cent. 
Similar experiments were carried out without the addition of calcium carbonate, using the same dust and also the dust from the Alpha Portland Cement Company already referred to. The results obtained were unexpected-with the former dust there was a decided increase of the water-soluble potash of the original sample, whereas with the latter there was an actual decrease. Table I gives the percentages of total potash in the dusts before treatment and the percentages of water-soluble potash before and after treatment at about $1000^{\circ}$ in a closed crucible, all expressed on the basis of the original sample.

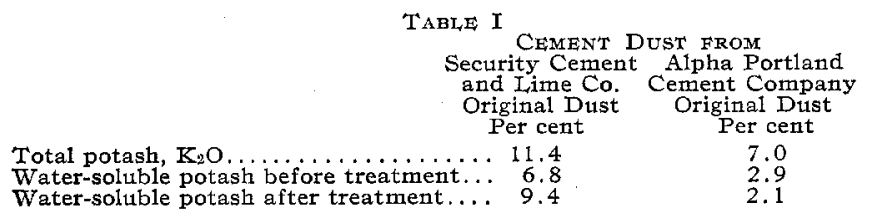

From Table I it may be seen that ignition of the Security dust in this manner has caused an increase of water-soluble potash from 60 to 82 per cent of the total potash in the un-ignited dust, while an identical procedure with the Alpha dust has brought about an actual decrease of water-soluble potash from $4 \mathrm{r}$ to 30 per cent. The method of ignition which was carried out as in the J. Lawrence Smith method precluded the loss of this potash by volatilization and the only conclusion to be drawn was that a further "recombination" of water-soluble potash takes place in the dust. controlled by use of a thermo-electric pyrometer and a rheostat in the circuit of the electrically heated muffle, and it was decided to make ignitions of the two cement dusts through a range of temperatures to ascertain the influence of differences of the temperature of ignition on the conversion of "recombined" potash into watersoluble potash or on the further recombination of watersoluble potash. As interest was centered on the behavior of the Alpha dust an initial experiment was run with this dust subjected for $40 \mathrm{~min}$. to a temperature of $600^{\circ}$. This experiment showed that instead of a diminution of water-soluble potash as obtained previously there was an increase thereof when the carbonaceous matter was removed by combustion. It is questionable that the recombination of potash can be attributed solely to the siliceous ash of the coal in the light of the above results. The writer hesitates to ascribe this effect to the carbon, however, because the Alpha dust also contains sulfides in some quantity, a fact forcibly presented when the dust was treated with hydrochloric acid. These sulfides no doubt also undergo change when the dust is ignited in an oxidizing atmosphere and it may be that they have an influence on the recombination of potash in the absence of air.

Table II contains the results of this series of experiments with the two dusts.

The readings of the pyrometer are probably not exact indications of the actual temperatures obtaining

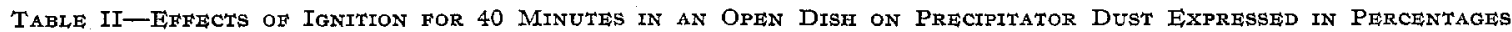

\begin{tabular}{|c|c|c|c|c|c|c|c|}
\hline \multirow[b]{3}{*}{ ON BASIS OF ORIGINAL, DUST } & \\
\hline & Untreated & & -7 & era & f Igni & & \\
\hline & Dust & $600^{\circ}$ & $700^{\circ}$ & $800^{\circ}$ & $900^{\circ}$ & $1000^{\circ}$ & $1100^{\circ}$ \\
\hline 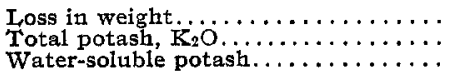 & $\begin{array}{rr}\cdots \\
\cdots & 1.40 \\
\ldots & 6.79\end{array}$ & $\begin{array}{r}5.69 \\
11.37 \\
9.36\end{array}$ & $\begin{array}{r}6.05 \\
11.42 \\
9.95\end{array}$ & $\begin{array}{r}6.40 \\
11.42 \\
10.18\end{array}$ & $\begin{array}{r}6.64 \\
11.27 \\
10.55\end{array}$ & $\begin{array}{r}7.32 \\
11.19 \\
10.62\end{array}$ & $\begin{array}{r}8.70 \\
10.99 \\
10.82\end{array}$ \\
\hline 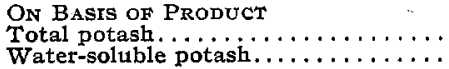 & $\begin{array}{rr}11.40 \\
\ldots & 6.79\end{array}$ & $\begin{array}{r}12.06 \\
9.93\end{array}$ & $\begin{array}{l}12.15 \\
10.59\end{array}$ & $\begin{array}{l}12.20 \\
10.88\end{array}$ & $\begin{array}{l}12.07 \\
11.30\end{array}$ & $\begin{array}{l}12.07 \\
11.46\end{array}$ & $\begin{array}{l}12.04 \\
11.85\end{array}$ \\
\hline
\end{tabular}

\begin{tabular}{crrrrrr} 
Untreated & \multicolumn{6}{c}{ Alpma Dust } \\
Dist & $600^{\circ}$ & $700^{\circ}$ & $800^{\circ}$ & $900^{\circ}$ & $1000^{\circ}$ & $1100^{\circ}$ \\
7.02 & 12.91 & 13.21 & 13.48 & 14.55 & 15.52 & 17.84 \\
2.93 & 4.98 & 6.97 & 7.00 & 6.48 & 5.97 & 5.38 \\
& 4.69 & 5.06 & 4.96 & 5.15 & 5.01 \\
7.02 & 8.02 & 8.03 & 8.09 & 7.58 & 7.07 & 6.55 \\
2.93 & 4.78 & 5.40 & 5.85 & 5.81 & 6.10 & 6.10
\end{tabular}

TAble III-Water-Soluble Potash In IgntTed Cement Dusts Expressed in Percentages of Total Potash Content

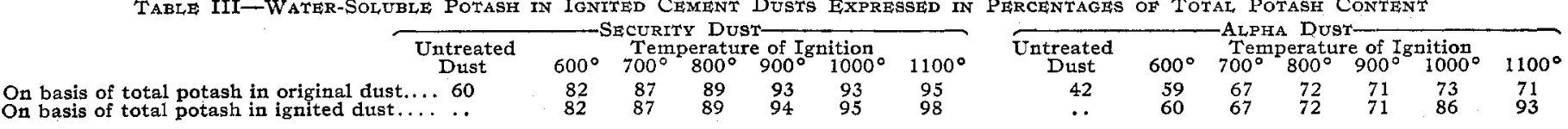

A glance at the dusts in their original condition before ignition would be sufficient to enable anyone to distinguish between them. The Security dust is ashgray in color while the Alpha dust is black, evidently containing unburnt carbonaceous matter. A sample of the latter dust was boiled with concentrated hydrochloric acid for 30 minutes, filtered on an alundum plate and a carbon determination was made on the residue. The carbon was found to form 9.26 per cent of the dust. Assuming the dust lost from the kiln to be 4 per cent of the raw mix, and $600 \mathrm{lbs}$. of raw mix as necessary to yield a barrel of cement, then the loss of carbon per barrel of cement produced amounts to $2.2 \mathrm{lbs}$. The view that this carbonaceous matter may have an influence on the behavior of the cement dust suggested the ignition of a sample of Alpha dust in an open dish placed in a muffle so that the carbonaceous matter might be burned up, combustion of this material not occurring to any great extent in the closed J. Lawrence Smith crucible. The temperature at which such ignition occurred could be approximately in the dishes. In the first place, it was evident that all parts of the muffle were not at a uniformly high temperature and, again, the temperatures locally produced by the combustion of the carbon in the Alpha cement dust may have been considerably in excess of the recorded temperatures. In consequence of this carbon content the manner of distribution of the sample in the dish may also have had an influence on the local temperatures of the samples. These same conditions, however, would obtain in large scale operations.

Table III shows that the ignition at temperatures of $600^{\circ}$ or over in an oxidizing atmosphere of treater dust from cement mills results in a liberation of the recombined potash of the dust and that this released potash (at $900^{\circ}$ ) amounts to 33 per cent of the total potash of the original dust in the one case and to 29 per cent in the other. In view of this fact it is considered possible that a procedure similar to this may find successful application on a manufacturing scale. The use of a kiln using oil or gas as a fuel is to be considered necessary for such operations, or if coal is used some arrange- 
ment whereby heat is supplied without contact of the fuel with the dust to be treated.

In case the dust is to be sold directly to the fertilizer trade such a process would have the advantage of yielding a product with its water-soluble potash more concentrated than in the original dust, for not only is the recombined potash liberated by this procedure but the total weight of the material is diminished. This diminution of weight may be attributed to loss of water, of carbon dioxide, and of any carbonaceous matter in the dust. If, however, the preparation of potash salts is aimed at, it is possible that for dusts behaving like the Alpha dust digestion under steam pressure, as mentioned above, would be the preferable method of treatment since in the latter method there is no volatilization of potash and the yield of water-soluble potash on the basis of the total original potash is consequently greater. This volatilization apparently commences at about $900^{\circ}$. As stated before, the temperatures of the Alpha dust very likely were considerably above those indicated by the pyrometer and relatively greater volatilization of potash in this dust at a given temperature may be easily explained on this assumption.

To ascertain the effect of time of heating on the two dusts, samples were ignited at $1000^{\circ}$ for 20,40 and 60 minutes. The results obtained are shown in Table IV.

TABLE IV-THE EFFECT ON WATER-SOLUBIE AND TOTAL POTASH CONTENT OF VARIATIONS IN DURATION OF IGNITION. TEMPERATURE $1000^{\circ}$ - Security DUST 20 min. 40 min. 60 min. 20 min. 40 min. 60 min.

On Basts of ORIGINAL DUST

\begin{tabular}{|c|c|c|c|c|c|c|}
\hline $\begin{array}{l}\text { Loss in weight....... } \\
\text { Total potash........ } \\
\text { Water-soluble potash. }\end{array}$ & $\begin{array}{r}7.06 \\
11.33 \\
10.60\end{array}$ & $\begin{array}{r}7.32 \\
11.19 \\
10.62\end{array}$ & $\begin{array}{r}7.37 \\
11.06 \\
.10 .58\end{array}$ & $\begin{array}{r}15.15 \\
6.12 \\
5.02\end{array}$ & $\begin{array}{r}15.52 \\
5.97 \\
5.15\end{array}$ & $\begin{array}{r}15.80 \\
5.89 \\
4.89\end{array}$ \\
\hline BASIS OF PRODUCT & & & & & & \\
\hline $\begin{array}{l}\text { Total potash ........... } \\
\text { Water-soluble potash. }\end{array}$ & $\begin{array}{l}12.19 \\
11.41\end{array}$ & $\begin{array}{l}12.07 \\
11.46\end{array}$ & $\begin{array}{l}11.94 \\
11.42\end{array}$ & $\begin{array}{l}7.21 \\
5.92\end{array}$ & $\begin{array}{l}7.07 \\
6.10\end{array}$ & $\begin{array}{l}7.00 \\
5.81\end{array}$ \\
\hline
\end{tabular}

It is apparent from inspection of this table that for the periods considered ignition of the dust for a longer period than 20 minutes has no decided effect on the ratio of water-soluble to total potash in the material.

\section{SUMMARY}

I-Dusts from cement mills using coal as fuel have considerable proportions of their potash content in a form not readily water-soluble.

II--Ignition of such dusts in an oxidizing atmosphere at temperatures of $600-1100^{\circ}$ converts the "recombined" potash into a readily water-soluble form.

III--For the periods considered ( 20 to 60 minutes) time of ignition apparently has little effect on the watersoluble potash content of the resultant product.

DefartMent OF Agriculture

BuREAU OF SoILS, Washington, D. C.

\section{EFFECT OF COAL ASH ON THE LIBERATION AND NATURE OF CEMENT MILL POTASH}

By N. S. Potrer, Jr., AND R. D. ChEESMAN

Received December 6, 1917

In all articles thus far published relating to potash as a by-product in the manufacture of cement, no consideration has been given to the potash content of the coal used in burning and its attendant effects. It is the purpose of this paper to point out the effect the coal ash has upon the liberation of potash in the kilns and upon the nature of the so-called "treater dust" collected.

The potash collected from the kiln stack gases where coal is used for burning appears in practically two forms, water-soluble potash and the insoluble or slowly soluble potash. The insoluble potash has been attributed to two causes: the potash in the unburned or partly calcined raw material carried over mechanically in the gases and to a recombination of the volatilized potash with the finely divided ash particles of the coal.

R. J. Nestell and E. Anderson in their paper, "The Nature of Cement Mill Potash,"' state that "the most important differences in the potash material from coalfired and oil-fired kilns, as shown by the analyses given, lie in the relative amounts of soluble and insoluble $\mathrm{K}_{2} \mathrm{O}$, and in the wide variation in potash concentration in the lighter fractions of dust obtained from kilns using these two different forms of fuel. In the dust from the oil-fired and coal-fired kilns previously referred to, where in the first case the per cent of insoluble $\mathrm{K}_{2} \mathrm{O}$ was 0.56 and in the second case 4.55 per cent, it seems safe to assume that the amount of mechanically carried-over raw material was practically the same, consequently the difference noted in the amount of siliceous material shown cannot be due to a greater amount of calcined raw mix in one case. The only other source of siliceous material is the ash from the coal used as fuel. Since this ash, coming as it does from finely powdered coal, must be in a state of extremely fine subdivisions, approaching that of a true fume, it is reasonable to suppose that part of this ash would be collected among the lighter portions of dust. Since approximately $9 \mathrm{lbs}$. of coal ash are introduced into the kiln per barrel of clinker burned, if only one-half this amount is carried out with the gases, it would still be sufficient to effect appreciably the composition of the collected dust, as the amount of dust caught per barrel of clinker produced is only about 20 lbs. Consequently it is probable that the considerable amount of insoluble potash shown to be present in the dust from the coal-fired kilns is in reality due to a combination of the volatilized potash with the finely divided incandescent particles of siliceous coal ash."

Wm. H. Ross, in his paper on "The Extraction of Potash from Silicate Rocks-II,", also states that "the slowly soluble combination is explained on the ground that during the burning of the cement part of the volatilized potash undergoes a recombination with the silicates in the dust."

The following is taken from an article on "The Recovery of Water-Soluble Potash as a By-product in the Cement Industry:" 3 "The insoluble potash represents the combinations occurring in the original silicates of the raw mix which is carried over mechanically in the dust before being subjected to a sufficiently high temperature to bring about decomposition. The form of combination which is slowly soluble in water is supposed to be due to a recombination of the volatilized potash with the silicates in the dust. In

1 This Journal, 9 (1917), 646.

2Ibid., 9 (1917), 467.

s Ibid., 9 (1917), 1035. 